\title{
'Candidatus Phytoplasma malaysianum', a novel taxon associated with virescence and phyllody of Madagascar periwinkle (Catharanthus roseus).
}

\begin{abstract}
This study addressed the taxonomic position and group classification of a phytoplasma responsible for virescence and phyllody symptoms in naturally diseased Madagascar periwinkle plants in western Malaysia. Unique regions in the 16S rRNA gene from the Malaysian periwinkle virescence (MaPV) phytoplasma distinguished the phytoplasma from all previously described 'Candidatus Phytoplasma' species. Pairwise sequence similarity scores, calculated through alignment of full-length $16 \mathrm{~S}$ rRNA gene sequences, revealed that the MaPV phytoplasma 16S rRNA gene shared $96.5 \%$ or less sequence similarity with that of previously described 'Ca. Phytoplasma' species, justifying the recognition of the MaPV phytoplasma as a reference strain of a novel taxon, 'Candidatus Phytoplasma malaysianum'. The 16S rRNA gene F2nR2 fragment from the MaPV phytoplasma exhibited a distinct restriction fragment length polymorphism (RFLP) profile and the pattern similarity coefficient values were lower than 0.85 with representative phytoplasmas classified in any of the 31 previously delineated $16 \mathrm{Sr}$ groups; therefore, the MaPV phytoplasma was designated a member of a new 16Sr group, 16SrXXXII. Phytoplasmas affiliated with this novel taxon and the new group included diverse strains infecting periwinkle, coconut palm and oil palm in Malaysia. Three phytoplasmas were characterized as representatives of three distinct subgroups, 16SrXXXII-A, 16SrXXXII-B and 16SrXXXII-C, respectively.
\end{abstract}

Keyword: Taxonomy; Classification; Phytoplasma; Virescence; Phyllody; Madagascar periwinkle. 